\title{
The Impact of Socio Economic Status on Emotional Intelligence and Creativity among Tribal Adolescent Students
}

\author{
Dr. Chandrakant Jamadar ${ }^{1}$, Sindhu A ${ }^{2}$
}

\section{ABSTRACT}

The present study is an attempt to investigate the conjoint off impact of Social Economic Status towards the prediction of Emotional intelligence and Creativity among tribal students. Accordingly,100 tribal samples, 50boys and 50girls of VIII, IX \& X class from Vivekananda Tribal Centre for learning(VTCL), Hosahalli, H.D.Kote, Mysore. The Socio Economic Status scale by Meenakshi(2004), Emotional Intelligence by Upinder Dhar(2010), and creativity test by Wallach-kogan. The results revealed that High Socio Economic Status students have more Emotional Intelligence and creative than the Low Socio Economic Status Students. Girls and boys have same level of Emotional Intelligence and Creativity. In Emotional Intelligence is no differences in three community students but in creativity Yerava Students have more creative than the other two community students.

Keywords: Socio Economic Status, Emotional Intelligence \& Creativity, Tribal adolescent's students.

The term, "tribe" originated around the time of the Greek city-states and the early formation of the Roman Empire. The Latin term, "tribes” has since been transformed to mean, “A group of persons forming a community and claiming descent from a common ancestor”.

The range of meanings however, has grown even further over the intervening years, for example, "Any of various systems of social organization comprising several local villages, bands, districts, lineages, or other groups and sharing a common ancestry, language, culture, and name” . Morris (1980) also notes that a tribe is a "group of persons with a common occupation, interest, or habit," and "a large family."

Today, the range of groups referred to as tribal is truly enormous. Not everyone however, can be deemed to be a member of a tribe. Those peoples who resisted joining in larger nation state entities were soon labeled by the nation states themselves to be "tribes." These people were "known to the world at large by names that have no relation to their own self-appellations.

\footnotetext{
${ }^{1}$ Assistant Professor, Post Graduate Department of studies in Psychology, Maharani Arts College for women, J. L. B. Road, Mysore, Karnataka

${ }^{2}$ Counselor, ACE Institute of creating Excellence, Bangalore

(C) 2015 I C Jamadar, Sindhu A; licensee IJIP. This is an Open Access Research distributed under the terms of the Creative Commons Attribution License (http://creativecommons.org/licenses/by/2.0), which permits unrestricted use, distribution, and reproduction in any Medium, provided the original work is properly cited.
} 


\section{The Impact of Socio Economic Status on Emotional Intelligence and Creativity among Tribal Adolescent Students}

\section{Tribal religion in Karnataka}

Tribal communities constitute about seven percent of the total population of India. These communities have variety and complexity in the belief systems as well as religious practices. Even these religions have historical antecedents which are documented in their oral epics and songs.

Tribal communities too have their legends about the birth and meaning of the universe. According to a scholar, tribal people believe that "The ultimate purpose of life is the creation of a meaningful order through imitation of the celestial model transmitted by myths and celebrated in rituals.”

Karnataka has a sizable population of tribal people. There are 34.64 lakhs tribal's distributed in various regions of Karnataka as per 2001 census. Raichur and Bellary contain large number of tribal communities. Toda, Beda, Soliga, Hakki-Pikki, Konda Kapu, Koraga, Bhils, Chenchu, Gonds, Maleru, Badaga, Hasala, Meda, Iruliga, Jenu kuruba, erava and siddis are some important tribes of Karnataka. All of them profess some religious beliefs and practice many rituals. A series of monographs published by Karnataka Sahitya Academy under the stewardship of Baraguru Ramachandrappa provide ample information about these tribes. Tribal religions and rituals are under constant pressure from the major organized religions. Some of this pressure is imposed deliberately and the rest is a consequence of exposure to the forces of modernization. In general, the tribes that remain geographically isolated are able to retain their traditional cultures and religions longer. On the other hand communities that are either nomadic or live in the periphery of civilized life are prone for drastic changes. Most of the tribal beliefs and rituals are highly localized and they are not influenced by the major religions. Attempts to influence them are foiled by changing the very fabric of the legends and stories to suit the tribal world. Consequently one finds tribal versions of Ramayana and Mahabharata scattered all over the country.

Many a time tribal customs and rituals are appropriated by the established religion and what emerges is a civilized version of tribal practices. Many Gods now worshipped by one and all were once the exclusive property of the tribal's. The attitude of tribal communities towards nature is now perceived as eco friendly and regarded highly. Many tribes worship tribal deities as well as the Gods of the Hindu pantheon. For instance Kadugollas, who worship gods such as Junjappa, Mattapan, Patappa, and Catalpa, are equally devoted to Siva, who is a part of their festivals and religious observances. Cult heroes from the past are also raised to the level of Gods and worshipped accordingly. Bedanayakas (Beda Nayaka) of Karnataka, worship Papanayaka, a deity supposed to have lived 300-400 years ago, as a holy man among them. He is attributed miraculous powers. Siddi community of North Canara which migrated to Karnataka from Africa has shed most of its original beliefs and adopted other religions. Now there are siddis belonging to Hinduism, Islam and Christianity. 


\section{The Impact of Socio Economic Status on Emotional Intelligence and Creativity among Tribal Adolescent Students}

\section{Tribal Population in Karnataka}

The tribal population of Karnataka increased to 34.64 lakh in 2001 from 19.16 lakh in 1991. The decadal growth rate during this period is a high 80.8 per cent, caused not by a spurt in fertility rates but by the addition of several new TRIBAL ADOLOSCENTS to the Scheduled TRIBAL ADOLOSCENTS (ST) category. The decadal growth rate is higher for females (81.9 per cent) than for males (79.8 per cent). The highest decadal growth rate occurred in Mysore district (around 328.0 per cent), Bagalkot (261.6 per cent), Dharwad (201.1 per cent) and Belgaum (193.0 per cent). The decadal growth rate is negative in Dakshina Kannada (-2.9 per cent). Raichur (18.1 per cent) has the highest percentage of ST population followed by Bellary (18.0 per cent), while Chitradurga (17.5 per cent), which had the highest percentage of ST population in 1991 came down to third place in 2001 on account of its bifurcation. The reverse is true of Raichur. Bellary has the highest population of Scheduled TRIBAL ADOLOSCENTS as a percentage of the ST population in the state (10.6) .

\section{Sex ratio in Karnataka}

The sex ratio for scheduled tribal adolescents (972), is higher than the all-India average (964) for as well as the state average (965), according to the 2001 census. There has been a perceptible improvement in the sex ratio of tribes since 1991, when it was 961. Among the southern states, Kerala performs well with 1,021, followed by Tamilnadu (980), Andhra Pradesh is below Karnataka with 971. The child sex ratio for the 0-6 age group is also higher (960), than the state average of 946. Culturally, there is greater gender equity among the scheduled tribal adolescents compared with the general population, which is largely shaped and driven by a male-dominated discourse that priorities son preference.

Across districts, one impressive finding is that Udupi (1023), has a sex ratio higher than Kerala's followed by Kodagu and Bagalkot (996), while Bangalore urban, typically, has the lowest sex ratio (913), followed by Haveri (941), Dharwad and Bijapur (944), and Bidar (950). In Bellary, which has the highest proportion of its population to the state's population, the sex ratio is 985 while Raichur, which has the highest percentage of population to the total population, is in fourth place with 993.

\section{Socio economic status of tribal adolescents in Karnataka}

Historically, the tribal economy was based on subsistence agriculture and/or hunting and gathering. However, since the tribal people treated land as a common resource, they rarely had land titles, and thus, lost their lands to outsiders when exploitation of forest resources began to take place on a significant scale. This ensured that a majority ended up as small and marginal landholders.

The 2001 Census data reveals that around half the ST population is in the workforce. Women constitute about 41.7 per cent of the workforce. More than 85 per cent of the working population 


\section{The Impact of Socio Economic Status on Emotional Intelligence and Creativity among Tribal Adolescent Students}

is in rural areas. The distribution of main workers (76.4 per cent) is concentrated in the rural parts of the state where a high 51.5 per cent work. Bellary has the highest percentage of main workers (11.5 percent) followed by Raichur (7.8 per cent). The highest percentage of ST marginal workers lives in Raichur (11.7), which also has the highest proportion of the ST population to the total population, clearly indicating their highly precarious livelihood status.

\section{Emotional intelligence in tribal adolescents of Karnataka}

Regarding the emotional state of adolescents, Goleman (1995), cited that "there is a world-wide trend for the present generation to be more troubled emotionally than the last; more lonely and depressed; more angry and unruly; more impulsive and angry and more nervous and prone to worry."'The tribes are economically inferior, uneducated at times and are less exposed to the modern world. Being the earliest inhabitant of the country, they have maintained a distinctive life style for centuries. Unfortunately the isolation has kept them out of mainstream and made them easy prey to exploitation ( Talesara 1994) and when they are forced to get along with the mainstream culture, they don't get adjusted easily. Kundu (1984) stated that lack of education and deprivation that these tribes face due to poverty may result in frustration both in personal as well as social relationships thereby resulting in poor self concept and low self esteem.

\section{Creativity in Tribes}

Creativity is common factors for all human being but in tribal people are different compare to common human being because of their culture, tradition, festival and painting, weaving and pottery, marks and their sculpture.

\section{METHOD}

\section{Statement of the Problem}

To study the impact of Socio-Economic Status on Emotional Intelligence and Creativity among Tribal Adolescent Students

\section{Need of the study}

Travel people are having their own history on the earth. They are entirely different from other peoples. Therefore, going to conduct a study on their Socio-economic Status levels have they are living? How much money they earn and how much they spend for their life? They given more importance to money or not? This money increases their Socio Economic Status Level so this factor is how influencing on their Emotional Intelligence and Creativity. Its explain the impact of Socioeconomic Status on their Emotional Intelligence and emotionally how they are? And creativity also we measure Total ambition of this study is how Socio Economic status is influence on tribal students, Emotional Intelligence and Creativity. 


\section{OBJECTIVES}

- To know the impact of Socio-Economic Status on Emotional intelligence and Creativity among tribal students.

- To understand the Gender and Age differences in Emotional Intelligence and Creativity in Tribal Students.

- To identify the Emotional Intelligence and creativity in different tribal community students.

\section{HYPOTHESIS}

H1 - There is significant effect /impact of Socio Economic Status on Emotional Intelligence and Creativity among tribal students.

H2 - There is significant differences in Emotional Intelligence and Creativity in Girls and Boys Tribal students

H3 - There is a significant difference in different class students in their Emotional Intelligence \& Creativity.

H4 - There is a significant difference in Emotional Intelligence and Creativity indifferent age group of tribal students.

H5 - There is a significant difference in Emotional Intelligence and Creativity in different tribal community students.

\section{Sample Design Tribal adolescent students}

\begin{tabular}{|c|c|c|c|c|c|c|c|c|}
\hline \multicolumn{2}{|c|}{ Gender } & \multicolumn{3}{|c|}{ Class } & \multicolumn{3}{|c|}{ Community } & \multirow[t]{2}{*}{ Total } \\
\hline Boys & Girls & 8 & 9 & 10 & $\begin{array}{l}\text { Jenu } \\
\text { Kuruba }\end{array}$ & $\begin{array}{l}\text { Kadu } \\
\text { Kuruba }\end{array}$ & Yerava & \\
\hline 50 & 50 & 28 & 30 & 42 & 49 & 26 & 25 & 100 \\
\hline
\end{tabular}

\section{Variables}

Independent variable $\quad$ : Socio - Economic Status, Tribal Adolescent Boys and Girls

Dependent Variable $\quad$ : Emotional Intelligence, Creativity

\section{Sample}

The sample consists of 100 from the different Haadi in H.D.Kote. In 100 samples, 50 from Girls,50 from Boys in different class students from the sample selected from Vivekananda Tribal Centre for learning (VTCL) in Hosahalli, Biramballi Post, H.D.Kote.

For the reason of this testing we taken permission from the Head Master and education officer VTCL Sargur. 


\section{The Impact of Socio Economic Status on Emotional Intelligence and Creativity among Tribal Adolescent Students}

\section{Procedure}

The test were administered to the adolescence tribal students in 10 Groups, 10 Subjects per group. Data collection was done in two sessions. In the first Session the Rapport was established with the Tribal Students and they were asked to introduce themselves. During the interaction with the teachers active cooperative from the Respective Class Teachers sought to get more conclusive environment with the tribal students. In the second session started after the first session with the 5 minutes rest, in this session first we administered socio economic status questionnaires, its taken 20minutes per group totally they taken 2 hours 40 minutes. After this questionnaire students taken5 minutes rest \& then we administered Emotional Intelligence questionnaires this also taken 10 minutes/group totally they have taken 1 hour 40 minutes and finally we administered creativity questionnaire its duration was also taken 15 minutes per group totally they have taken 2 hours 30 minutes. Total Time taken is 6 hours and 45 minutes for their response.

Finally this research data collected was done in a day.

\section{Tools Used in the Study}

Meenakshi (2004), Socio Economic Status Scale (SESS). This scale consists of 7 Parts and Part-I consists of education, II part Profession, III Part monthly Income, IV Part total wealth is cash this every sub scales consists of 10 Items and V part measures property is this scale consists 5 items, Part VI measures surrounding locality its consists 21 items and last part measures social status its consists 5 items.

Upinder Dhur (2010), Emotional Intelligence Scale (EIS). This scale consists of 34 items and its measures is differentiated factors like self ownerness, empathy, Self-motivation, emotional stability, managing relations, integrity, self development, value orientation, commitment and altruistic behavior.

\section{Creativity Test}

Creativity test is designed to measure the level of creativity (verbal and non verbal), based on Wallach -Kogan creativity test.

\section{Statistical Techniques}

In this study, we used some statistical methods for analysis and discussion. They are mean,SD , $\mathrm{t}$-value and ANOVA are used. 
RESULTS AND DISCUSSIONS

Table: 1 values of mean, SD and t-value to show the effect of Socio-Economic Status on Emotional intelligence and creativity. (N-100)

\begin{tabular}{|c|c|c|c|c|}
\hline \multirow{2}{*}{ Group } & \multicolumn{2}{|c|}{ Emotional Intelligence } & \multicolumn{2}{|c|}{ Creativity } \\
\hline & HSES & LSES & HSES & LSES \\
\hline Mean & 48.84 & 44.94 & 49.10 & 44.90 \\
\hline SD & 7.31 & 7.92 & 8.27 & 6.85 \\
\hline t-value & \multicolumn{2}{|c|}{$* 2.5634$} & \multicolumn{2}{|c|}{$* 2.7699$} \\
\hline
\end{tabular}

*Significant at 0.01 level HSES- high socio economic status LSES- low socio economic status

The above table shows that, the Mean \& SD of Emotional Intelligence \& Creativity in High Socio Economic Status \& Low Socio Economic Status the Mean and SD of Emotional Intelligence in High Socio Economic Status is 48.84 and 7.31, and Mean Score of Low Socio Economic Status is 44.90 \& 7.92 respectively. It shows that who have High Socio Economic Status they are good in their Emotional Intelligence. And who have low Socio Economic Status they are poor in their Emotional Intelligence. They are more Emotional Intelligence it shows that High Socio Economic status students are have more emotional intelligence than the Low socio economic status students. The calculated t-value is 0.01 level. It is significant at 0.0001 level. Therefore, the "formulated hypothesis is that "There is Significant impact of Socio Economic Status on Emotional Intelligence in tribal Students". Hence, the formulated Hypothesis is strongly accepted. The result shows that Socio Economic Status is Highly Impact on Emotional Intelligence in Tribal Students. Who have high socio economic status they are good in emotional intelligence because of their family factor, environmental factors is good \& their parents are economically high and they got all facilities from media and other channels. So emotionally they are balanced but who have low Socio Economic status they are poor in their emotional intelligence, because of their poor financial level, they doesn't get any facilities, they are not good in their emotional intelligence.

In Creativity in High Socio Economic Status Mean score is 49.10 and 8.27 and low Socio Economic Status is 44.90 and 6.85 respectively. It shows that who socio are economically good they are good in their creativity also. The t- value of creativity is 2.76 it is significant at 0.01 level.

The "formulated hypothesis is that there is significant impact of Socio Economic Status on tribal Students Creativity”. The formulated hypothesis is accepted. The social and economic levels of the tribe communities are not homogenous. But they are at different levels of variability, but cannot be uniform. The development schemes have to be devised in the light of socio-cultural factors and economic needs of the tribes in each region and sometimes each community. The 


\section{The Impact of Socio Economic Status on Emotional Intelligence and Creativity among Tribal Adolescent Students}

socio cultural matrix of tribal communities in our country exhibits distinct systems and traditions. Among the tribal communities, traditional values and social ethos play an important role and significance of social, cultural factors cannot be ignored in formulation of schemes for their all round sustainable development. Kaur (1992), was studied the interrelationship between creativity, intelligence and academic achievement of $11^{\text {th }}$ grade boys and found that relationship between creativity and intelligence was low but positive; academic achievement commonly influenced the correlation between creativity and intelligence; relationship between creativity and intelligence was non linear; low positive relationship existed between creativity and academic achievement; creativity commonly influenced the correlation between academic achievement and intelligence; the relationship between intelligence and academic achievement was linear.

Table: 2 shows values of Mean, SD and t-value of shows the differences of Emotional Intelligence and Creativity of Tribal Students in related to Gender. $\quad(\mathbf{N}-100)$

\begin{tabular}{|l|l|l|l|l|}
\hline \multirow{2}{*}{ Group } & Emotional Intelligence & Creativity \\
\cline { 2 - 5 } & Girls & Boys & Girls & Boys \\
\hline Mean & 137.24 & 141.65 & 1.83 & 2.07 \\
\hline SD & 17.89 & 16.92 & 0.57 & 1.26 \\
\hline t-value & $* 1.2636$ & $* 1.2480$ & \\
\hline
\end{tabular}

*It is not significant

The above table shows that, the Mean \& SD of Emotional Intelligence in tribal Girls is 137.24 and SD is 17.89. It shows that girls have high level of emotional intelligence. In boys the Mean score is 141.65 and 16.92 respectively. it shows that boys have high level of emotional intelligence than the girls. The calculated t-value of Emotional Intelligence is 1.26, it is not significant. Therefore, the formulated hypothesis is that "there are significant differences in their Emotional Intelligence. Hence, the formulated hypothesis is not accepted, but, according to Emotional Intelligence scale. More than 85 that is High level of Emotional Intelligence. In this Research, both have high level of Emotional Intelligence. But, According to result there is no significant differ. Because, in adolescent's tribes was found to be poor and differ in Gender, the probable reason behind this may be attributed to the adherence of tribes to their culture. A strong sense of community belongingness in them and confinement to their cultural values and norms may restrict them to get involved with the changing outside the world. Tribes are primitive and prefer living in isolation. i.e. in remote areas or deep forests. Which generally cutoff from other civilized areas. Hence, the tribal's have limited contact with near the city people and society. The habit of isolation helps to preserve them to their social customs and traditions to a larger extent.

Especially Girls in tribes they are very traditional and they are strictly following customs and another important thing is they have no freedom in their family because they are lower the 


\section{The Impact of Socio Economic Status on Emotional Intelligence and Creativity among Tribal Adolescent Students}

Emotional Intelligence than the boys, and family type also be a factor for lower Emotional Intelligence. As tribes have a family of precautions in which nuclear family setup is coming. In joint families adolescents find more opportunities to develop personal, interpersonal and social adequacy and thus become more emotional stable. These results are in time with Audichya (2005), who found that adolescents develop culturally defined traits. In tribes the parents prepare their children's for arranging the basic physiological needs only these culture do not address the emotional needs to be developed. This can be supposed by Maslow (1976), as that he stated that when physiological needs are not met, psychological needs take a backseat. Thus in tribal culture; less stress is given on emotional skills enrichment and hence, resulting in poor level of emotional intelligence away tribal adolescents. Table No.2 shows that the Mean score of girls is of creativity in tribal girls is 1.83 and SD is 0.57 . Creativity in boys 2.07 and 1.26 respectively. It shows that Boys have more creative than the Girls. The t-value of creativity is 1.24. It is not significant, therefore, the formulated hypothesis is that "there is significant differences between girls and boys in their creativity” hence, the formulated hypothesis is not accepted. According to result there is no significant differ, because in Adolescents tribes was found to be poor and differ in gender. The probable reason behind this may be attributed to the adherence of tribes to their culture. A strong sense of community belongingness in them and confinement to their cultural values and norms may restrict them to get involved with the changing outside the world. Tribes are primitive and prefer living in isolation. i.e. in remote areas or deep forests. Which generally cutoff from other civilized areas. Hence, the tribal's have limited contact with near the city people and society. The habit of isolation helps to preserve them to their social customs and traditions to a larger extent.

Girls in tribes they are very traditional and they are strictly following customs and beliefs another important thing is they have no freedom in their family, because they are lower the Creative than the boys, and family type also is a factor for lower Creativity. Different manifestations of the impact of culture on creativity are discussed and illustrated by empirical studies. They include: (i) conceptualization of creativity on both the explicit and implicit levels; (ii) attitudes towards creativity and values attached to creativity; (iii) channeling creative endeavor through different domains of human activities; and (iv) socialization processes and educational goals and practices. It is argued that creative expression is a universal human phenomenon that is firmly grounded in culture and has its own profound impact on culture itself. The effects of culture on creativity. 


\section{The Impact of Socio Economic Status on Emotional Intelligence and Creativity among Tribal Adolescent Students}

Table-3: Values of Mean, SD and t-value to show the differences in Emotional Intelligence \& Creativity of different class Tribal Students (200)

\begin{tabular}{|l|l|l|l|l|l|}
\hline Group & Mean & SD & N & \multirow{3}{*}{ F- Value } \\
\hline \multirow{3}{*}{$\begin{array}{l}\text { Emotional } \\
\text { Intelligence }\end{array}$} & X & 145.11 & 17.4 & 28 & \multirow{3}{*}{$* 2.87$} \\
\cline { 2 - 5 } & IX & 140.17 & 16.5 & 30 & \\
\cline { 2 - 5 } & VIII & 135.14 & 17.4 & 42 & \multirow{3}{*}{$* 2.656$} \\
\hline \multirow{3}{*}{ Creativity } & X & 2.21 & 1.38 & 42 & \\
\cline { 2 - 5 } & IX & 1.77 & 0.47 & 30 & \\
\cline { 2 - 5 } & VIII & 1.75 & 0.51 & 28 & \\
\hline
\end{tabular}

* It is significant, at 0.05 level

The above table Shows that the Mean and SD of Emotional Intelligence in different class Tribal students. The Mean \& SD score of Emotional Intelligence in Xth Standard Tribal Students is 145.11 and SD is 17.4. It shows that Xth Standard students have high level of emotional intelligence. In IXth Standard Tribal Students Mean Score is 140.17 and SD is 16.5. And in VIIIth Standard Tribal Students mean is 135.14 and SD is 17.4 respectively. It shows that Emotional Intelligence is different from different classes. Here it shows that $\mathrm{X}^{\text {th }}$ Standard students have more emotional intelligence compare to VIII ${ }^{\text {th }}$ and IX $^{\text {th }}$ Standard students. The Fvalue of emotional intelligence is 2.87. It is significant at 0.05 level. Therefore ,the "formulated hypothesis is that there is significant differences in different class students in their emotional intelligence", hence, the formulated hypothesis strongly accepted but according to Emotional Intelligence Scale more than 85 score that is high level of Emotional Intelligence in this research.. In this research, they have high level of Emotional Intelligence. According to result it's differ from the different classes. The adolescent tribal students are differe from class to class here $\mathrm{X}^{\text {th }}$ standard students are have free from feelings And VIII ${ }^{\text {th }}$ Standard students have high emotional intelligence according to norms but compare to $\mathrm{IX}^{\text {th }}$ and $\mathrm{X}^{\mathrm{h}}$ Students they are emotionally stable. Because of the reason is the person take emotional decision depends on his experience and age factors. And depends on the age factors students learn which are right or wrong. Especially on Tribal Students age factor is influencing very much. The Authors Table No.3, shows that the Mean \& SD of Creativity in different classes in tribal students are from VIII $^{\text {th }}$ Standard Students Mean is 1.75 and SD is 0.51 and in IX $^{\text {th }}$ Standard Tribal Students Mean is 1.77 \& SD is 0.47 and finally $\mathrm{X}^{\text {th }}$ Standard students mean is 2.21 \& SD is 1.38 respectively. It shows that creativity is different classes. Here it shows VIIIth Std students have low creativity compare to $\mathrm{IX}^{\text {th }}$ Std, but $\mathrm{IX}^{\text {th }}$ Std students have less creativity compare to $\mathrm{X}^{\text {th }}$ Std students. The $\mathrm{F}$ value of creativity is 2.65 . It is significant is at 0.05 level. Therefore, "the formulated hypothesis is that there is significant difference in different class students in their creativity". Hence, the formulated hypothesis is accepted, and according to result it's differing from different classes therefore it is significant. Because the age factor of tribal students is influencing on their creativity and its depend on the classes. It compare to VIII and IX standard, Xth standard students are more creative.. Because of age factors and level of intelligence. Especially in tribal 


\section{The Impact of Socio Economic Status on Emotional Intelligence and Creativity among Tribal Adolescent Students}

students are very creative but depends on the age factor they are more creative the result are in time with Gakhar, S.C.E' Manhas, K. D.(2006), "Emotional Intelligence as correlates to intelligence, creativity and academic achievement”, Department of Education, Punjab University, Chandigarh. The study would reveal significant trends as to the degree an extend of predictability and relationship of Emotional Intelligence, Creativity and academic achievement and will motivate the educationists and curriculum framers to design academic as well as other activities in a way that those will foster the ability of adolescents to face challenges of life right from the school stage. The present study was conducted on a sample of 400 XI class male and female adolescents from government and private schools situated in urban and rural areas of Jammu and Kashmir. It was found that there is positive general intelligence and Emotional Intelligence ( $\mathrm{r}=208)$ also from the result, adolescents creativity was positively and significantly correlated with their Emotional Intelligence (r-610) there is also significant positive correlation is also obtained between academic achievement and Emotional intelligence $(r=0.128)$.

Table: 4 Shows the Values of Mean, SD and t-value to show the differences in Emotional intelligence and creativity in different age group Tribal students. $(\mathrm{N}=100)$

\begin{tabular}{|l|l|l|l|l|}
\hline Group & \multicolumn{3}{|l|}{ Emotional Intelligence } & Creativity \\
\hline & $12-15$ & $16-19$ & $12-15$ & $16-19$ \\
\hline Mean & 135.04 & 143.79 & 1.82 & 2.08 \\
\hline SD & 16.92 & 17.24 & 0.46 & 1.28 \\
\hline t-value & $* 2.5735$ & \multicolumn{2}{|c|}{$* * .1 .3227$} \\
\hline
\end{tabular}

*. It is significant at $0.01 * *$. It is not significant

The above table Shows that, the Mean and SD of Emotional Intelligence in different Age Groups of Tribal Students In age group of 12-15 mean score is 135.04 and 16.92 and in 16-19 age group is Mean score is 143.79 and 17.24 respectively. It shows that $16-19$ age groups have more emotional intelligence compare to 12-15 age group students. The calculated t-value of Emotional Intelligence is 2.57. It is significant at 0.01level. Therefore, "the formulated hypothesis is that there is a significant difference on Emotional Intelligence in different age group of Tribal students". Hence, the formulated hypothesis is strongly accepted according to emotional intelligence scale more than 85 score that is high level of emotional intelligence. In this research, they have high level of emotional intelligence but according to result, it differs from different age group but especially in 16-19age groups tribal students are high in emotional intelligence compared to 12-15 age group tribal students. Because it depends on their age group, and environment, family factors also influencing them. Cooper and Sawaf (1997), define emotional intelligence as the ability to sense, understand and effectively apply the power and acumen of emotions as a source of human energy, information, connection and influence. Mayer and Salovey(1993) define emotional intelligence as the ability to monitor one's own and others feelings and emotions to discriminate among them, and to use this information to guide one's 


\section{The Impact of Socio Economic Status on Emotional Intelligence and Creativity among Tribal Adolescent Students}

thinking and action. Emotional intelligence involves the ability to perceive accurately, appraise and express emotions; the ability to access and generate feelings when they facilitate thoughts: the ability to understand emotions and emotional knowledge and intellectual growth.

Table No.4 Shows the Mean \& SD of Creativity in different Age In 12-15 Age groups Tribal students Mean score is 1.82 \& SD is 0.46 and 16-19 Age group Tribal Students is 2.08 \& SD is 1.28 respectively. It shows that 16-19 age group students have more creative compare to 12-15 age group Tribal Students. The t-value of creativity is 1.32 . It is not significant. Therefore, "the formulated hypothesis is that there is a significant difference of creativity in different Age group in Tribal Students”. Hence, the formulated hypothesis is not accepted. According to result it is not significant because of their age group in Adolescent Tribal Students are creative but compare to their age groups who are having 16-19 Age group they are more creative than the 12-15 Age group students. Age factor influenced on creativity. Therefore, it depends on the level of Environment, Family, Age group are influencing their level of creativity.

Table: 5. to shows the values of Mean, SD and t-value to show the differences in Emotional Intelligence and Creativity in different tribal community students.

\begin{tabular}{|l|l|l|l|l|l|}
\hline Group & & Mean & SD & N & \multirow{2}{*}{ F- Value } \\
\hline \multirow{3}{*}{$\begin{array}{l}\text { Emotional } \\
\text { Intelligence }\end{array}$} & Jenu Kuruba & 139.38 & 20.60 & 35 & \multirow{3}{*}{1.53} \\
\cline { 2 - 5 } & Kadu Kuruba & 138.97 & 16.00 & 35 & \\
\cline { 2 - 5 } & Yerava & 139.73 & 15.00 & 30 & \\
\hline \multirow{3}{*}{ Creativity } & Jenu Kuruba & 1.72 & 0.49 & 33 & \multirow{3}{*}{$* * 3.816$} \\
\cline { 2 - 5 } & Kadu Kuruba & 1.82 & 0.48 & 35 & \\
\cline { 2 - 5 } & Yerava & 2.33 & 1.54 & 32 & \\
\hline
\end{tabular}

* It is not Significant

** Significant at 0.01 level

The above table shows the Mean and SD of Emotional Intelligence in different Tribal Community Students. The Mean and SD score of Jenu Kuruba is 139.38 and SD is 20.60, and in Kadu Kuruba Mean score is 138.97 and SD score is 16.00 and finally in Yerava Mean score is 139.73 and SD score is 15.00 respectively. It shows that Jenu Kuruba and Yerava Tribal Community Students have more Emotional intelligence than the Kadu Kuruba. The t-value of Emotional Intelligence is 1.53. It is not significant. Therefore, "the formulated hypothesis is that there is significant difference in different tribal community student's in Emotional Intelligence". Hence, the formulated hypothesis is not accepted. But, according to Emotional Intelligent Scale. More than 85 score i.e. high level of emotional intelligence. In this research, they have high level of emotional intelligence. But, group there is no significant differ. Because, tribal peoples have limited contact with the city peoples. Since their childhood they doesn't know how to react their feelings and emotions. Because it's causing of their daily life style and their work influences. Depend on their Family and Peer groups and Social Contact. And creativity Shows the mean and 


\section{The Impact of Socio Economic Status on Emotional Intelligence and Creativity among Tribal Adolescent Students}

SD of different tribal community students. The mean and SD of creativity in Jenu Kuruba is $1.72 \&$ SD is 0.49 and in Kadu Kuruba Mean is 1.82 \& SD is 0.48 and finally Yerava Mean is 2.33 \& SD is 1.54 respectively. It shows that Yerava community students have more creativity than the Kadu Kuruba and Jenu Kuruba community students. The t-value of creativity is 3.81. it is significant at 0.01 level. Therefore "the formulated hypothesis is that there is a significant difference in different tribal community student's creativity”. Hence the formulated hypothesis is strongly accepted according to result also it is significant at 0.01 level. The reason is tribal community people are creative because of their genetic; environmental a family factors are influencing their creativity. Yerava are more creative because they are away from Forest Areas and have contact with civilized peoples.

\section{CONCLUSION}

The survey research aim to investigate the impact of socio-economic status on emotional intelligence and creativity among Tribal students. It shows tribal peoples Socio Economic status towards their emotional intelligence and creativity in Mysore district and HD kote rural areas especially in Tribal colony the study provides sample evidence that the overall Socio Economic Status of these Students shows Emotional and Creativity are depend on their Socio Economic Status.

The socio economic status of tribal students is highly impact on their emotional intelligence and creativity and in emotional intelligence and creativity in tribal boys and girls both is same. No differences between them and the emotional intelligence and creativity between class students $\mathrm{x}$ students are emotionally stable and have more creativity compared to VIII and IX std students and in age group, 16-19 age group tribal students are emotionally stable and more creative compare to 12-15 age group of tribal students. Finally, in tribal community peoples, especially Yerava Community students are have more emotional intelligence and creativity compared to Kaadu kuruba and Jenu Kuruba tribal communities.

* HSES students have more Emotional Intelligence and creative then the LSES students.

* Girls and Boys have same level of Emotional Intelligence and Creativity.

* In EI there is no difference in three community students but in creativity Yerava Students have more creative than the other two community students.

\section{RECOMMENDATIONS}

This section represents recommendations for Tribal Peoples. Tribal peoples are away from society living with their own cultures, customs and traditions. They don't think their education and socio economic status. They are leading their life without planning. Therefore government and welfare authorities give them more opportunities and to bring them into main stream of society develop, well culture, well establishment of language, Mental health training, psychosocial training, national overseas scholarship, Technical oriented education to children and improve their life style and mind setup. 


\section{REFERENCE}

Aiyyappan, A. (1948), Report on the Socio-Economic Conditions of the Aboriginal Tribes ofthe Province of Madras, Govt. of Madras, Madras.

Albert, R.S.; Runco, M.A. (1999), "A History of Research on Creativity". In ed. Sternberg, R.J. Handbook of Creativity. Cambridge University Press.

Audichya Suman (2005), Social, Emotional Maturity and Social Acceptance of Adolescents.

Ph.D. Thesis Unpublished. Udaipur: Maharana Pratap University of Agriculture and Technology.

Bailey, F.G.(1960), Tribe, Caste and Nation, Oxford University Press, Bombay.

Baron-Cohen, S. (1995), Mind-Blindness, MIT Press.

Baruch, I., Hemsley, D., and Gray, J. (1988a), 'Differential performance of acute and chronic schizophrenics in a latent inhibition task', Journal of Nervous and Mental Disease, 176, 598-606.

D.D. Nag.(1958),Baiga Economy of Madhya Pradesh, M.K. Publications, Calcutta, Dean Joros (1973), Socialisation of Politics, Higgim Bofhem, Madras.

Department of the Dravidian \& Tribal Welfare, Ministry of Tribal Affairs by Indian Government.

Fried, Morton.(1975), The Notion of Tribe. Menlo Park,CA: Cummings Publishing Company

L.C. Mohanthy.(1989), An Analysis of the improved Economic Life of Tribals of Orissa and the way towards Integration, Deep and Deep Publishers.

L.P Vidyarthi.(1970), Socio-cultural Implication ofIndustrialisation in India, Planning Commission, New Delhi.

Maslow A. (1976), Theory of motivation and hierarchy of needs. In: LA Jelle (Ed.): Personality Theories:Basic Assumption, Research and Applications. Boston: Mc Graw Hill Publications.

Mitra, Aparna.(2008), Status of Women among Scheduled Tribes in India. Journal of Socioeconomics, Vol.370 (3), pp.1202-1217. Morris.(1980), p. 1369.

S. Ramamani.(1988),Tribal Economy Problems and Prospects, Chough Publications, Allahabad.

Saxena, R.P. (1964), Tribal Economy in Central India, K.L. Mukhopadhaya, Calcutta.

Sharma, R.S.(1980), Indian Feudalism, MacMillan India Ltd., Delhi.

Sinha, Surajit.(1965), '·Tribe-caste and Tribe-Peasant Continua in Central India". Manin India, 42.

Tribal Sub-Plan and Article 275(1) of the Constitution. Tribe - Wikipedia, the free encyclopedia

Upindhar Dhar.(1971), Emotional Intelligence Scale (EIS), National Psychological Corporation, Kacheri ghat, Agra.

Vidhyarthi, L.P. and B.N.Rai.(1977a), The Tribal Culture in India, Concept Publishing Company, Delhi.

Vimal Shah.(1969), Tribal Economy in Gujarat, Well Print Publications, Jaipur. 